\title{
Analysis of EPR Policy Effect under Different Charging Modes
}

\author{
Yanyan Shao* \\ Department of Management Science and Engineering, East China University of Science and \\ Technology, Shanghai, China \\ *210569945@qq.com
}

\begin{abstract}
The paper explores the impact of charging models and its environment on the effects of EPR policy from the perspective of promoting the recycling industry based on system dynamics research. The dissertation sets up three kinds of charging modes: "government non-intervention mode", "charging mode" and "charging + innovation incentive mode". And select two indicators "consumer green preferences" and "old parts recyclability", simulating four implementation environments of EPR policy according to their value. The results show that in order to promote the development of auto parts remanufacturing, it is necessary for the government to intervene in the design of EPR policy based on charging mode. Among them, "charging + innovation incentive model" has a significant effect on promoting EPR policy incentives. Consumer green preferences and old parts recyclability will affect the incentive effect of charging mode on the EPR policy, and its impact is different. Therefore, under different implementation environment of policy, different charging modes need to be chosen to have a strong guiding role on recycling and remanufacturing.
\end{abstract}

Keywords: EPR policy; charging mode; charging + innovation incentive model; environment.

\section{Introduction}

Extended Producer Responsibility (EPR)refers to the expansion of the producer's environmental responsibility from the production process to the product life cycle, especially the waste recycling and final disposal after product consumption, thereby promoting environmental protection throughout the product life cycle [1].

Scholars have carried out a certain degree of research around the effects of EPR policy. More research is based on the EPR policy to explore the impact of subsidy policies on promoting resource reuse. Mitraa and Webster [2] analyzed practices of new product manufacturing and remanufacturing in the context of government subsidies. WenhuiZhou[3] has implemented a fund subsidy plan based on EPR to solve the problem that unqualified recyclers occupy the recycling market, and concluded that a larger subsidy does not necessarily lead to greater benefits. Plambeck [4] studied the effectiveness of sales-based and recovery-based subsidy policies. Sheu [5] researched promotion of government subsidies to the coordination and cooperation of supply chain members through the analysis of Taiwan's electronics industry. Mitra [6] compared the government's subsidies to different objects through the game model for producers and remanufacturers. Aksen [7] established the government's supportive subsidy model and the legislative subsidy model.

In view of this, this paper will use the theory, method and modeling tools of system dynamics to explore the impact of different charging models on EPR policy effects, and explore the feasibility and effectiveness of the simulated charging model and its implementation environment by changing the policy implementation environment. Sexuality reveals the mechanism of the impact of the charging model and its implementation environment on the recycling and remanufacturing industry, thus providing theoretical guidance for the design of China's EPR policy.

\section{Problem Description and Stock Flow Chart}

The "production-recycling and remanufacturing" system can be divided into three subsystems: production link, recycling and remanufacturing, and EPR policy under the entire EPR policy.

Based on the causal relationship of the above three subsystems, a stock flow chart as shown in Fig. 1 is established. 


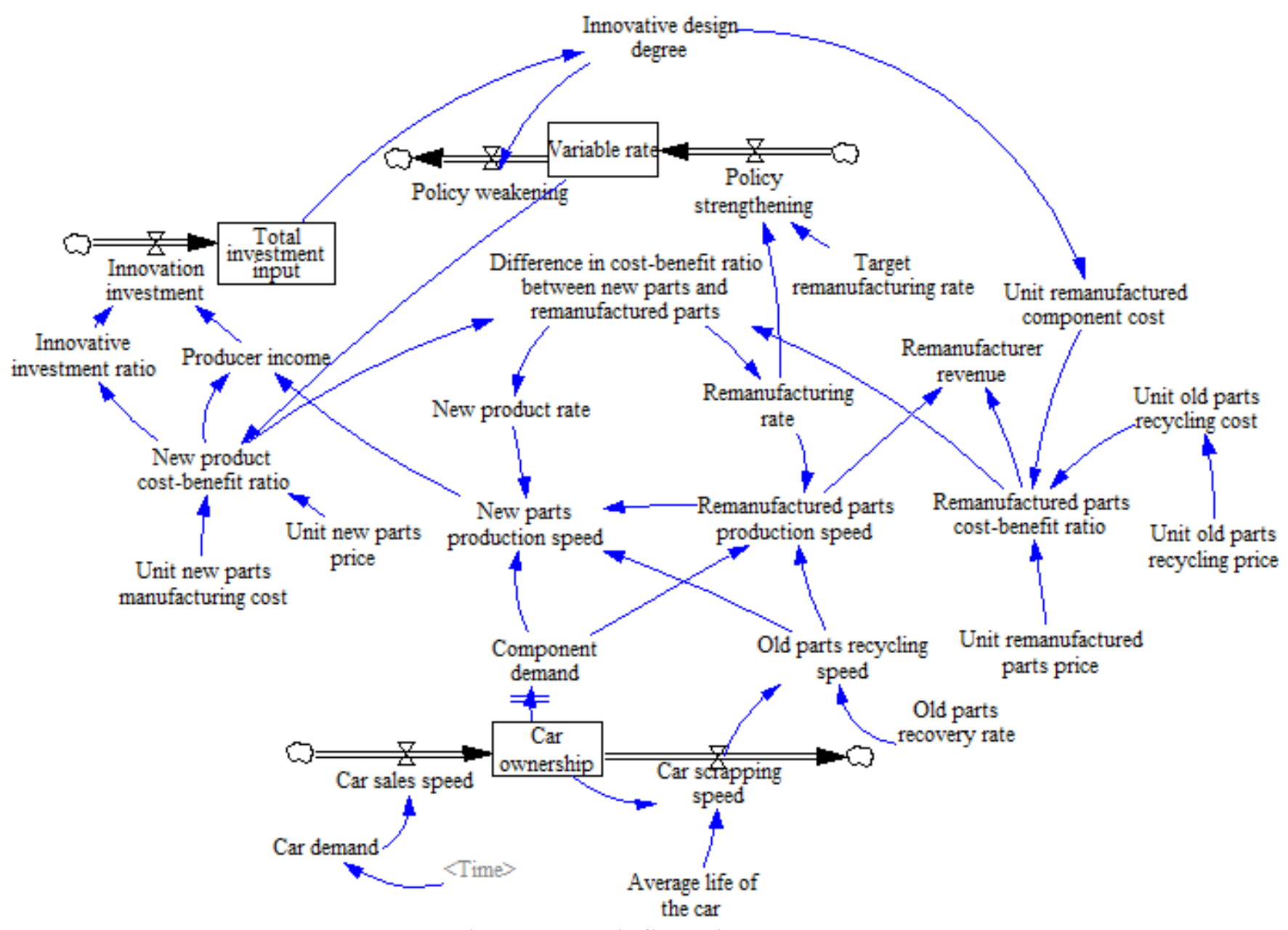

Figure 1. stock flow chart.

\section{Simulation Analysis}

The simulation was performed using Vensim PLE software, and the simulation time was set to 30 years in steps of 1 year. This paper selects the production speed of remanufactured products as an indicator to measure the incentive effect of EPR policy. In the case of certain market demand, producers and remanufacturers provide new products and remanufactured products to meet market demand. The production speed of remanufactured products can reflect the development of back-end remanufacturing, so it is chosen as a measure of the impact of the charging model. An indicator of the effectiveness of EPR policy incentives.

(1) Charge mode setting

In order to explore how "the charging model affects the incentive effect of EPR policy", this paper designs three charging modes.

Mode 1 is the "Government Non-Intervention Model", Mode 2 is the "charge model", Mode 3 is the "charge + innovation incentive model".

(2) Setting of policy implementation environment

This paper selects the "consumer green preference" and "old piece recoverability" indicators to characterize the policy implementation environment.

According to the consumer green preference and the old piece recoverability, the implementation environment of the EPR policy is divided into four categories, labeled LL market (A); HL market (B); LH market (C); HH market (D). 


\subsection{Analysis of the Impact of the Charging Model}

(1) Scenario analysis of government non-intervention

Analysis 1: In the case of non-intervention by the government, since the cost-return ratio of new parts is higher than the cost-return ratio of remanufactured parts, the demand for parts and components in the market is all satisfied by the manufacturers, so in order to promote China's auto parts Government development is necessary for the development of remanufacturing.

(2) Analysis of the impact of the "charge model"
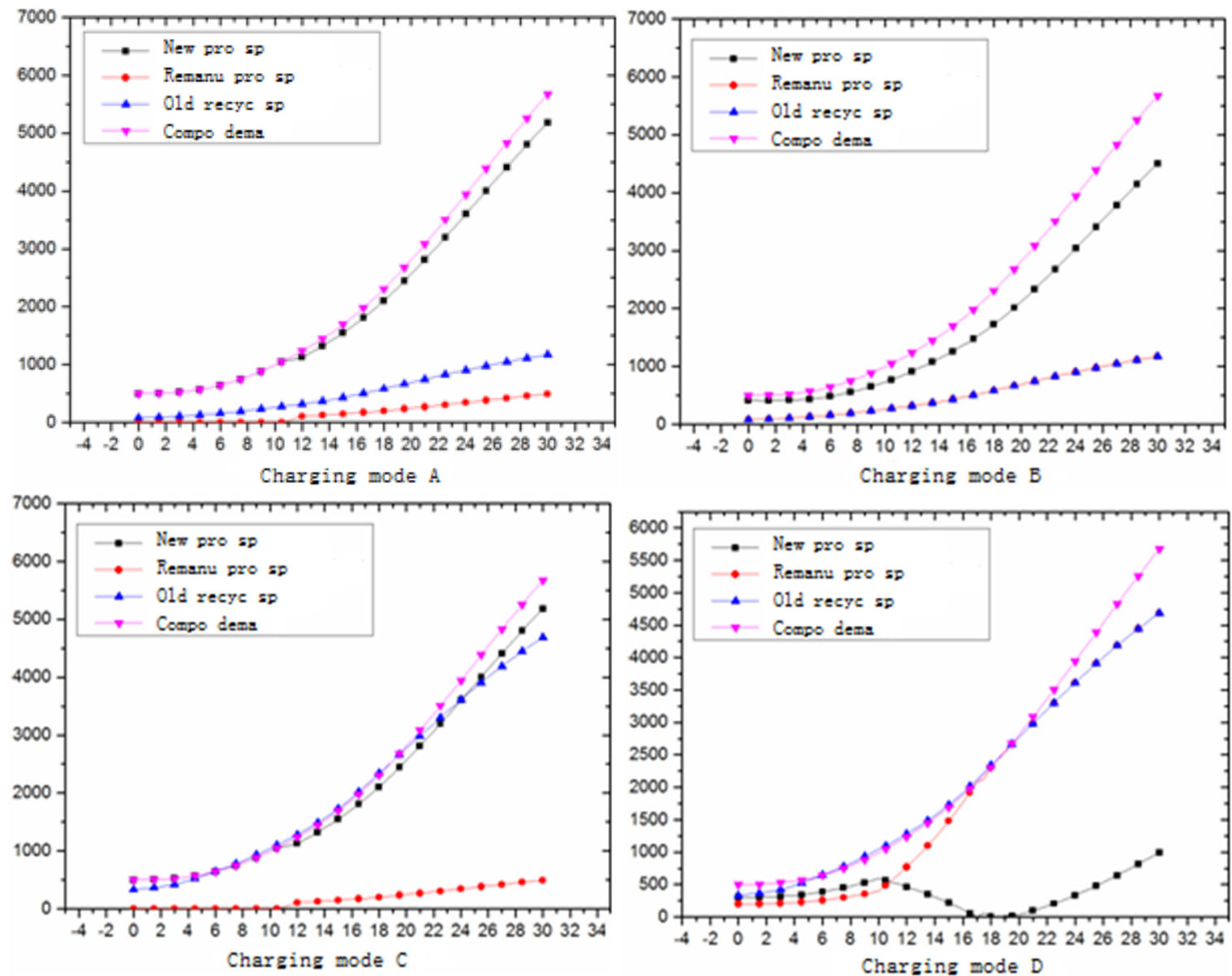

Figure 2.Simulation results under "Charging Mode".

Analysis 2: Based on the "charge model" EPR policy, when the fee strength reaches a certain level, there is a better policy effect. Its policy guiding role is closely related to the implementation environment. Its guiding role is weak in the environment with low green preferences of consumers, and its guiding role is strong in the environment of high green preference and high recovery rate.

(3) Analysis of the Impact of "Charge + Innovation Incentive Model"

Analysis 3: The "Charge + Innovation Incentive Model" can enhance the incentive effect of EPR policy on back-end recycling and re-manufacturing. This guiding effect is more obvious when consumers have low green preferences.

\subsection{Analysis of the Impact of Consumers' Green Preferences}

Analysis 4: Consumer green preference has an impact on the implementation of EPR policy. High consumer green preference can promote the incentive effect of EPR policy. In the environment with low recoverability rate of old parts, the promotion effect is weak; the old parts can be recycled. In a higher rate environment, the promotion effect is stronger. 


\subsection{Analysis of the Impact of the Recoverability of Old Parts}

Analysis 5: The recoverability of old parts has an impact on the implementation of EPR policies. The high recoverability of old parts can promote the incentive effect of EPR policy on remanufacturing. The lack of recycling of old parts will seriously limit the incentive effect of EPR policy on remanufacturing.

\section{Analysis Conclusion}

Based on the system dynamics model of the impact of the built charging model on the incentive effect of EPR policy, this paper designs two different charging models for four different policy implementation environments. The results show that:

(1) In order to promote the development of remanufacturing, government intervention is necessary, that is, the government design of EPR policy based on the charging model is necessary.

(2) The incentive effect of the two charging modes on the EPR policy is different. In general, the "charge + innovation incentive model" is more effective in incentivizing the EPR policy than the "charge model", that is, the guiding effect on recycling and remanufacturing is stronger. . What the two charging models have in common is that their incentive effect on EPR policies is related to the policy implementation environment.

(3) The implementation effect of the EPR policy based on the charging model is affected by the policy implementation environment. The policy implementation environment is characterized by two factors: the old piece recoverability rate and the consumer green preference.

\section{Acknowledgments}

This work was financially supported by National Natural Science Fund.

\section{References}

[1]. Organisation for Economic Co-operation and Development. Extended Producer Responsibility: A Guidance Manual for Governments[M]. OECD Publishing, 2001.

[2]. Mitra S, Webster S. Competition in remanufacturing and the effects of government subsidies[J]. International Journal of Production Economics, 2008, 111(2): 287-298.

[3]. Zhou W, Zheng Y, Huang W. Competitive advantage of qualified WEEE recyclers through EPR legislation[J]. European Journal of Operational Research, 2017, 257(2): 641-655.

[4]. Plambeck E, Wang Q. Effects of e-waste regulation on new product introduction[J]. Management Science, 2009, 55(3): 333-347.

[5]. Sheu J B. Bargaining framework for competitive green supply chains under governmental financial intervention[J]. Transportation Research Part E: Logistics and Transportation Review, 2011, 47(5): 573-592.

[6]. Mitra S, Webster S. Competition in remanufacturing and the effects of government subsidies[J]. International Journal of Production Economics, 2008, 111(2): 287-298.

[7]. Aksen D, Aras N, Karaarslan A G. Design and analysis of government subsidized collection systems for incentive-dependent returns[J]. International Journal of Production Economics, 2009, 119(2): 308-327. 